\title{
Delayed subdural hematoma after recovery from dengue shock syndrome
}

Sir,

Dengue virus is a single-stranded RNA virus belonging to flavivirus genus. Dengue infection causes dengue fever (DF), dengue hemorrhagic fever (DHF), and dengue shock syndrome (DSS). DSS is the severe presentation of DF and is characterized by critical vascular leak and circulatory collapse. It carries high mortality risk with death occurring within $24 \mathrm{~h}$ of the onset of shock. ${ }^{[1]}$ Few reports on the occurrence of subdural hematoma (SDH) associated with dengue virus infection have been reported. However, the delayed occurrence of the SDH after recovery from DSS has not been reported. Here, we report a young male patient who recovered from DSS, but returned within one month with spontaneous SDH.

A 21-year-old male patient was brought to the Emergency Department in December 2014 with a history of fever of 5 days and an altered state of consciousness of 1 day. Fever was intermittent and high grade. He had petechial rashes over trunk and extremities. There was no vomiting, loose stools, or seizures. On systemic examination, he had tachycardia with tachypnea and hypotension. His extremities were cold and clammy. He had mild hepatosplenomegaly. Neurologically, he was stuporous with minimal movement of all limbs to painful stimulus. There was no neck stiffness and no other lateralizing or localizing deficits. He was put on mechanical ventilation and started on double ionotropes with intravenous fluids. Brain computed tomography (CT) was normal. Complete hemogram showed leukocytosis (14,500 cells/cumm) with platelet count of $80,000 /$ cumm. Renal function test showed creatinine of $1.4 \mathrm{mg} / \mathrm{dl}$. Liver function tests were suggestive of transaminitis (aspartate aminotransferase: $110 \mathrm{IU} / \mathrm{l}$; alanine aminotransferase: $156 \mathrm{IU} / \mathrm{l})$. Coagulation profile showed deranged international normalized ratio 1.62. Serum dengue nonstructural protein1 and dengue-specific immunoglobulin $\mathrm{M}$ antibody were positive. Cerebrospinal fluid analysis was not done due to hemodynamic instability. A diagnosis of DSS was made based on the clinical and investigational profile. He made a slow recovery over the next 3 weeks and was weaned off from the ventilator. At discharge, he was conscious, ambulatory with normalization of liver functions, platelet counts, and coagulation abnormality. In February 2015, he started having headache, which was holocranial, episodic, lasting for $1-2 \mathrm{~h}$, and getting relieved with an analgesic. Headache became continuous with projectile vomiting 5 days before presenting to us. Fundus examination showed blurring of disc margins in both eyes. There was no neck stiffness or other lateralizing or localizing deficits. Magnetic resonance imaging (MRI) brain showed left frontoparietal SDH region with no mass effect or midline shift [Figure 1]. He was treated with analgesics and anti-edema measures. He had symptomatic improvement and was discharged.

Four serotypes of dengue virus have been recognized. Infection with one serotype does not confer immunity to the subsequent infection with other serotypes. However, it causes severe disease manifestation such as DHF or DSS. DHF presents with bleeding manifestations including intracranial hemorrhages and epidural spinal hematoma.

Kumar et al. reported a patient who presented with atypical acute SDH due to DHF. ${ }^{[2]}$ Mittal and Jain reported a 27-year-old patient with DF who had clinical features suggestive of aseptic meningoencephalitis and within 6 days developed bilateral SDH and pure motor quadriparesis due to axonal polyneuropathy. ${ }^{[3]}$ Jain et al. reported a 22-year-old patient who presented with clinical features suggestive of DSS and had associated spontaneous acute SDH. He succumbed to the illness. ${ }^{[4]} \mathrm{A}$ study by Bhoi et al. on cranial CT and MRI changes in dengue encephalitis reported
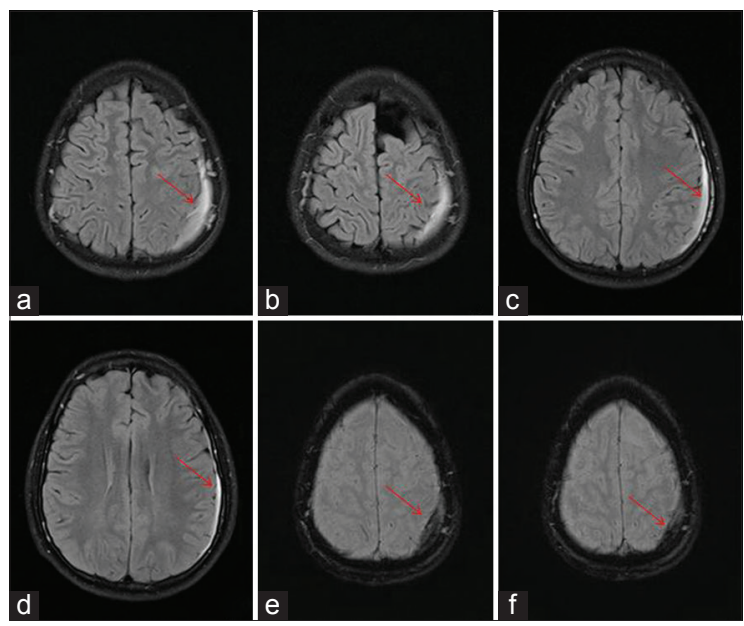

Figure 1: Brain magnetic resonance imaging fluid-attenuated inversion recovery imaging axial view (a-d) shows left frontoparietal subdural hematoma with no mass effect or midline shift (red arrow); (e and f) gradient echo shows bleed 
one patient with DSS who had cerebellar hematoma and $\mathrm{SDH} .{ }^{[5]}$

To conclude, our patient had recovered from DSS and subsequently presented with left spontaneous thin $\mathrm{SDH}$, which was managed conservatively. This delayed presentation of SDH after recovery from DSS has not been reported.

\section{Acknowledgment}

The authors thank the Department of General Medicine and Neurosurgery in aiding in the management of the patient.

\section{Financial support and sponsorship}

Nil.

\section{Conflicts of interest}

There are no conflicts of interest.

Rohan R. Mahale, Anish Mehta, Abhinandan K. Shankar, Rangasetty Srinivasa Department of Neurology, MS Ramaiah Medical College and Hospital, Bengaluru, Karnataka, India

Address for correspondence: Dr. Rohan R. Mahale,

Department of Neurology, MS Ramaiah Medical College and Hospital, Bengaluru - 560 054, Karnataka, India. E-mail: rohanmahale83@gmail.com

\section{References}

1. World Health Organisation. Dengue Haemorrhagic Fever; Diagnosis, Treatment, Prevention, and Control. Geneva: WHO; 1997.

2. Kumar R, Prakash O, Sharma BS. Dengue hemorrhagic fever: A rare presentation as atypical acute subdural hematoma. Pediatr Neurosurg 2008;44:490-2.

3. Mittal M, Jain N. Subdural haematoma and axonal polyneuropathy complicating dengue fever. BMJ Case Rep 2011;2011. pii: Bcr1220103672.

4. Jain N, Gutch M, Kumar V, Naik AK. A fatal combo of dengue shock syndrome with acute subdural hematoma. Neurol India 2012;60:105-6.

5. Bhoi SK, Naik S, Kumar S, Phadke RV, Kalita J, Misra UK. Cranial imaging findings in dengue virus infection. J Neurol Sci 2014;342:36-41.

This is an open access article distributed under the terms of the Creative Commons Attribution-NonCommercial-ShareAlike 3.0 License, which allows others to remix, tweak, and build upon the work non-commercially, as long as the author is credited and the new creations are licensed under the identical terms.

\begin{tabular}{|l|l|}
\hline \multicolumn{2}{|c|}{ Access this article online } \\
\hline Quick Response Code: & Website: \\
\hline & www.ruralneuropractice.com \\
\cline { 2 - 2 } & \\
\hline
\end{tabular}

How to cite this article: Mahale RR, Mehta A, Shankar AK, Srinivasa R. Delayed subdural hematoma after recovery from dengue shock syndrome. J Neurosci Rural Pract 2016;7:323-4. 